\title{
A Method of Extracting Organizational Components for Aligning Information Technology with Business
}

\author{
Azmat Ullah ${ }^{* 1}$, Richard Lai ${ }^{2}$ \\ ${ }^{1}$ La Trobe University, School of Business, Melbourne, Vic. 3086, Australia. \\ Australia. \\ * Corresponding author. Email: A.Ullah@latrobe.edu.au; lai@cs.latrobe.edu.au \\ Manuscript submitted January 10, 2018; accepted March 8, 2018. \\ doi: 10.17706/jsw.13.7.374-385
}

2 La Trobe University, Department of Computer Science and Information Technology, Melbourne, Vic. 3086,

\begin{abstract}
Structuring a good working relationship between business and information technology (IT) is synonymous with structuring good alignment. Alignment refers to the degree of fit between business and IT to reach a common business goal. However, it has long been accepted that establishing strong alignment is a complex task due to a lack of information on how organizational components can be extracted. Organizations consist of key components such as model, strategy, operations, processes etc. Processes in business operations are stable key elements which need to be well managed and fit optimally with the proposed business strategy and other related organizational activities. This paper presents a method of extracting organizational components for the purpose of achieving better Business/IT alignment and describes how we have applied it to a medical inventory system. Successful business process extraction will typically provide information for the following: what needs to be included in the process; why businesses need a process; who the process stakeholders are; how to implement the process; and how well an Information System (IS) supports its business process.
\end{abstract}

Key words: business process extraction, business process modeling, IS requirements, business-IT alignment, IS development, bubble diagram.

\section{Introduction}

Over the past several years, researchers have paid an increasing amount of attention to the importance of alignment between business and Information Technology (IT). Alignment can be defined as the optimized synchronization between dynamic business objectives and respective technological support by IT. Successful alignment may result in better business performance for the organization [16], [17]. However, achieving strong alignment has long been regarded as a complicated task by alignment researchers and business executives[18], as alignment is an adaptive method within the firm rather than an event, requiring an ongoing effort of long term business process planning, the reengineering of business goals/objectives, and business process formulation that supports and shapes the system requirements. Consequently, business process management is required.

Business process management (BPM) is a standard to manage and to improve business processes in organizations. The term BPM might be new but the concept of business process has a rich history. It first originated in Fredrick Taylor's theories of scientific management that appeared in the early 1920s [4]. Ever since, scholars have studied the issue of BPM in organizations which has resulted in the availability of 
different BPM techniques today such as [2], [7]-[15]: business process modeling, business process reengineering, business performance management, workflow, six sigma, etc. After a comprehensive literature survey on the issue of alignment and BPM, we believe that the concept of extracting business processes and business process modeling in the context of alignment has not been previously studied in great depth. Only a few researchers have examined the business process modeling issue [1-3, 29], but, so far, there is no published work on business process extraction from the perspective of alignment between business and IT [18].

Extracting business processes in alignment research is the art of discovering business processes in depth, which includes: firstly, who the process stakeholders are, which client will be paying for the implementation of the process, which users will interact with the process, and which developers will implement the process. It secondly examines why business needs processes including business goals and objectives. Thirdly, where a process is going to be used, it discovers the business organization environment. Fourthly, when business needs a process, it discovers the process development timeframe. Therefore, the in-depth extraction of business processes is required prior to deriving the system requirements from the process and to develop the Information Systems (IS) [19]-[21], [18].

This paper presents a method of extracting organizational components for the purpose of achieving better Business/IT alignment and describes how we have applied it to a medical inventory system. Successful business process extraction will typically provide information for the following: what needs to be included in the process; why businesses need a process; who the process stakeholders are; how to implement the process; and how well the IS supports the business process.

\section{The Context of our Work}

In this paper we model the business environment for better alignment between business and information technology. This section summarized the key concepts used in this research: the business process modelling and alignment.

\subsection{Business Process Modeling}

Processes in business operations are stable key elements which need to be well managed and fit optimally with the proposed business strategy and other related organizational activities. In other words, a business process is basically a standardized approach to convert a set of user inputs into a design output, for instance, a loan application at a bank, as shown in Figure 1, where a customer applies for a bank loan via an electronic application form. This information becomes the input into the loan application process. The bank process, at this stage, consists of several important pillars such as a credit check, customer details, technological support and other activities to enable the bank to make a decision as to whether to approve the loan or not. The output of the bank process is the decision that is communicated to the customer.

Business process extraction in the field of process management is the art of discovering the process stakeholders and all the processes, including the goals, which motivate the development of a software system that fulfills the proposed process implementation. A process stakeholder is an individual or organization that will either gain or lose from the success or failure of a software system, such as clients who pay for the development of the process, users who interact with the system to do their work, and developers who implement and maintain the system. Stakeholders who are clients and users play a pivotal role in the extraction of business process, as usability can only be defined in terms of the location where the process is going to be used and in terms of the targeted user population. Moreover, the method of identifying goals within the process focuses the system analysts on the process problem domain and the needs of the stakeholders rather than on solutions to those problems. Clients often have difficulties articulating their business process. Therefore, it is the IS analyst's responsibility to identify information 
about the goals that the clients currently use in the process and those they might want to include in the process.

Business process modeling is referred to as a collection of techniques and methodologies that are used to model the system's behavior and its requirements. In other words, process modeling is a language which is used to identify organizational goals that need to be achieved. The language is derived from a modeling language known as the Extended Enterprise Modeling Language (EEML). It is a useful technique by which to capture, clarify and link the business goals of an organization. Linking goals within the business process is a complex task, as one business process can carry more than one goal, as shown in Figure 3. Therefore, it is important that every goal within the business process is explored and linked with others for better clarification of the process. To model the business process, we used business process modeling notation (BPMN). The language was developed by the business process management initiative group and is widely accepted by business analysts and business process researchers [22].
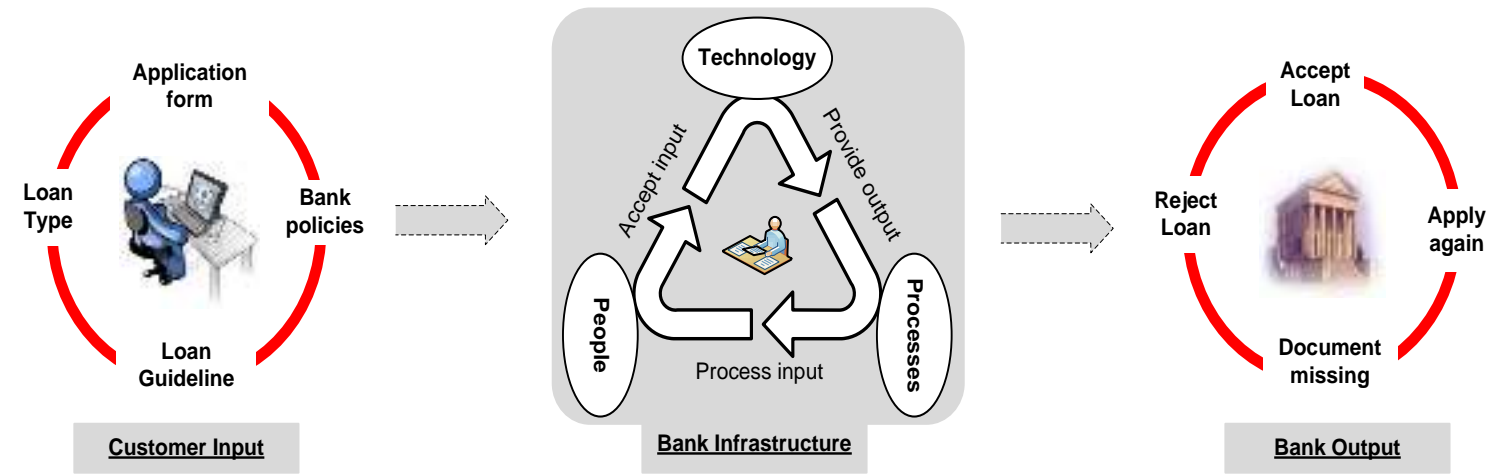

Fig. 1. How the business process works.

\subsection{Business-IT Alignment}

The notion of alignment refers to the optimized synchronization between dynamic business objectives and respective technological support by IT. However, attaining successful alignment between IT and business is always a critical process, as pointed out by business executives and managers. The concept first appeared in the early 1970s and since then, researchers have tried to understand the issue by studying various organizational factors. Using early techniques, alignment researchers struggled to address the issue through linking the business plan with the information technology plan. However, these techniques were ad hoc, given the level of dissatisfaction in organizations regarding their respective IT departments. The principal disadvantage of early techniques was the way the business and IT structure was planned. Early on, planning was only divided into top-down and bottom-up processes, for example, on the business side, planning was sub-divided into different departments such as HRM, finance, marketing, IT etc., and on the information technology side, the structure was divided into hardware and software, to establish the link between business and information technology [23-24]. These theories have expanded over time and nowadays, researchers point out many issues and have proposed various suitable alignment models and approaches.

Moreover, alignment can be examined from different perspectives representing different organizational factors such as: structure [25], culture [26], strategy [27], and social aspects [28]. In relation to the organization's structure, scholars considered complex structures, and quick changes in structure. In relation to the organization's culture, they examined lack of communication, weak relationships and lack of IT belief within the organization. In relation to the organization's strategic directions, factors such as formal business 
and formal IT strategy were considered in terms of alignment. In relation to the social aspect of the organization, factors such as a lack of shared domain knowledge, a lack of IT knowledge in the business department and a lack of business knowledge in the IT department were considered. Further to the alignment concept overview, alignment can be categorized into different phases, where every phase represents a precise part of the organization, such as internal or external phase, department phase, project phase etc. In the external phase, the organization is aligned with the business partner organizations including customers, traders, competitors etc. In the internal phase of alignment, the organization's departments are alignment with each other. This kind of alignment could be organization phase alignment, department phase alignment, business project phase alignment, system development phase alignment etc.

\section{Related Work}

The label of BPM might be new, but the concept has a rich history. Literature shows that scholars developed the theory of BPM in three separate waves. The concept first originated in Fredrick Taylor's theories on scientific management that appeared in the early 1920s. At this time, the business process was standardized rather than automated and processes were implicit in work practices [4]. The second wave of business process management was developed by Michael Hammer and James Champy in the 1990s, where business processes were starting to be automated through enterprise resource planning (ERP) and various other standards of the systems [5]. Recently, Smith and Fingar introduced the third wave of process management, where business processes are considered the essential hub and fundamental building block of all automation and business systems. In this wave, organizations focus on change, particularly on how to apply changes to business processes, when business staff lack IT knowledge [6]. Moreover, in the third wave of process management, scholars studied several other related concepts as follows: Business Process Modeling [7]-[9], Business Process Reengineering [10], [11], Business Change Management [14], Business Performance Management [12], [13], Six Sigma [15], Workflow [2] etc.

After a comprehensive literature survey on the issue of Business-IT alignment and conducting a survey on BPM, we believe that the concept of business process extraction and business process modeling in the context of alignment has not been previously studied in great depth. Only a few researchers have examined the business process modeling issue, collectively producing a good deal of work such as EKD, goal-based workflow, goal-based business process models and requirements engineering approach for IT-Business alignment $[1,2,3,33]$. However, to date, there has been no published work on business process extraction from the perspective of alignment between business and IT. Enterprise Knowledge Patterns (EKD) is the language used in the requirements engineering analysis phase to model the business processes, for example, what needs to be included in the proposed process and how to link goals within the process. The technique is composed of several sub-models such as: business role model, process model, goal model, actor's model, resource model, etc. The method of goal-based workflow suggests a business process modeling infrastructure for system requirements engineering in regard to clarifying the organizational goals/objectives and to understanding the current organizational situation. The business process-driven requirements engineering approach is a technique to derive the system's requirements from the organizational model by means of business process modeling, where two stakeholders participate, including: BPMN to link the business and IT processes and the goal tree to model the business process in a way that is easy for IT to understand. Recently, we [29] presented a business process driven requirements engineering approach for IT to better understand system requirements, as requirements are automatically generated from the business process and provide assistance to obtain the systems requirements quickly. The approach guarantees the development of an IT system that effectively fulfills the needs of the business, which positively influences the process of IT-Business alignment. 
However, these approaches have several drawbacks. First and foremost, the existing approaches assume that a business process is in place before modeling occurs. This raises a very basic question: how can we perform best business process modeling if the processes are not well extracted [18]. Consequently, business process extraction which clearly defines the following information: what the process is all about; what needs to be included in the process; why businesses need a process; who are the process stakeholders; how to implement the process etc, is important before modeling it. Second, they do not provide adequate information on business processes, as one business process is a combination of different sub-processes or goals that need to be explored in order to analyze the business process completely.

\section{The Method}

Organizations have their own unique way of conducting business and these unique ways are captured in the business processes of the organization. The processes in the business are primary elements of organizational success. However, although effectively managing business processes is a key activity for business prosperity, there remains huge gaps in understanding how to drive business efficiency through a process approach. Building a comprehensive and clear understanding of business processes, how they function, and how to manage them remain key issues in modern businesses. To overcome these issues in business processes, senior management invests a huge part of the company's budget in information technology resources because they believe the method of organizing business processes suffers due to poor IT support. This raises a fundamental question underlying these conversions: how can an IT department actually help business to implement their processes if they lack information on process extraction and process modeling.

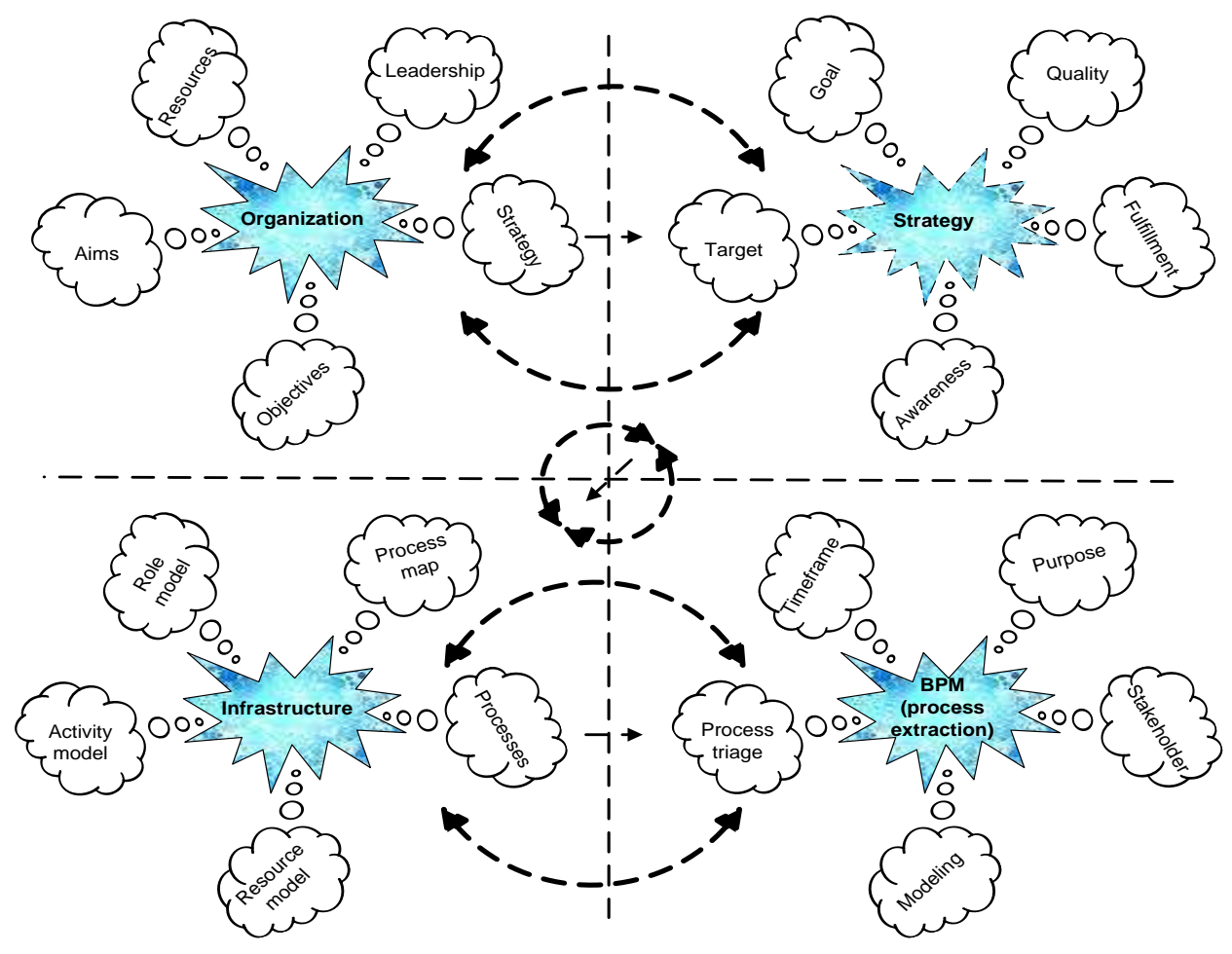

Fig. 2. The method.

The aims of this method are twofold: firstly, to extract the business process which includes: what problems need to be solved in the process?; how to identify the process and system boundaries?; who is the 
process stakeholder?; why processes need to be implemented?; and where is the process going to be used?; and secondly, to identify the process in detail and establish a process hierarchy including goals, which is known as business process modeling. This planned method can be divided into two: the extraction of the overall enterprise, and the extraction and modeling business process, as shown in Figure 2. Part 1 describes the specifications of the overall enterprise, which consist of the specification of three major components: the organization, the business strategy, and the business infrastructure. All these components must be in concordance to assure IT-Business alignment. The extraction concept for part 1 of the method is based on the bubble diagram and our previous work [18]. Part 2 depicts the way to extract the business process in detail, which is known as process extraction. Part 2 is divided into three stages. Stage 1 extracts the business process in the form of a mission statement of the process (purpose); who is the stakeholder of the process (stakeholder)?; and when the process is required (timeframe)? Stage 2 analyzes the business process in the form of process triage. Stage 3 describes the way to model the business process in order to identify all included goals within the selected business process and established hierarchy among them.

\subsection{Extraction of Enterprise Architecture}

Organizational architecture is defined as a design or a description that develops clear associations between the company product, company processes, services, and information technological infrastructure, in context with a complete definition of the organization. The term 'organization' refers to the group of people who formally work together to achieve the business goals and objectives. The business goals and objectives cannot be accomplished individually; therefore, the organization infrastructure needs to be formed. Generally, scholars divide the concept of organization into two types: formal, which represents organizations which have legal and official recognition; and informal which are used to represent the private part of the organization. The method extracts the organizational environment by means of organizational aims, objectives, leadership, resources, and organizational strategy. The organizational aims and objectives are used to map long and short range business goals, which are the goals that help to achieve the organizational mission statement. Leadership represents the process in which one or more persons use the employee workforce to accomplish organizational tasks. Resources describe the organizational rules and regulations, and finally the business strategy is used to present the organizational plans.

Strategy is a long or short term plan of action in the business that aims to achieve a particular goal or set of goals. Defining and extracting a business strategy is always a difficult task for business executives and managers. As a consequence, various techniques such as [16, 31-32], have appeared in the literature in order to support business strategy definition, strategy modeling, and extraction of strategy. In the second stage of the method, business strategy has been extracted by means of organizational scope (aims); who are your customers and what are their needs (strategic target and goals); are the customers aware of the company product (awareness); how to evaluate the strategy (fulfillment); and how to maintain company achievements in the market (quality).

Business infrastructure guarantees the appropriate synchronization of human resources, finances, processes and all other operational tools that are necessary to ensure manageable, profitable growth. Once the organizational environment and the business strategy have been extracted, the method extracts the business infrastructure, as shown in Fig. 2, comprising a role model, process map, activity model, processes, and a resource model. A role model is a standard model that is used to measure the organizational actors' roles and responsibilities, where each role defines a set of activities within the process. In the process map, we introduced a further three sub-models: the business strategy process, which defines the managerial scope and organizational planning; the operative process, which is used to create a link between product development and service provision; and the support process which identifies the organizational resources and their measurement. The activity model represents the organizational activities that have been used to 
work with partner organizations including clients, dealers, competitors etc. The process model is used to define a complete and dynamically synchronized set of mutual and transactional activities that bring value for the consumers. Finally, the resource model presents the most vital notions of the organizational domain that are used within processes, such as rules and regulations.

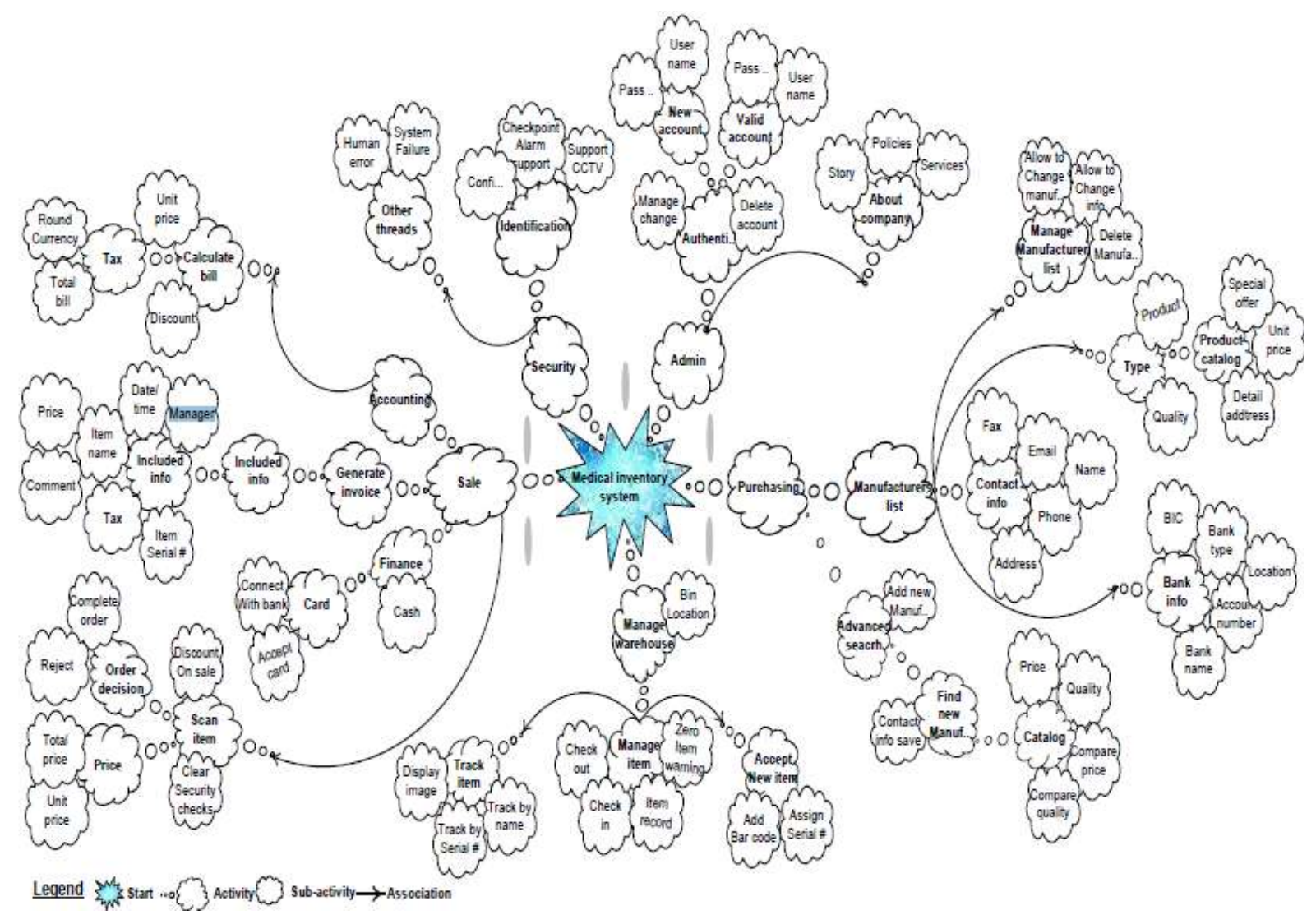

Fig. 3. Process of medical inventory system in a medical company.

\subsection{Business Process Management}

Business process management (BPM) is the method used to tie together all organizational elements to ensure a successful business environment within the organization. Moreover, BPM is a management practice that provides support to companies in order to model, organize, and optimize their business processes for significant growth. A number of techniques have appeared in the literature to manage the business processes [2], [4]-[15], but problems still exist due to rapid changes in the business environment, particularly in relation to changes in consumer services, technologies and product lifecycles. To overcome these issues, organizations continuously update their business processes in response to market demand; for example, in the $60 \mathrm{~s}$, the predominant organizational concentration was to produce quantity, in the $70 \mathrm{~s}$ to produce low cost products, in the 80 s to produce quality products, in the 90 s to produce products in less time, and in the 21st century, the organizational process has changed towards offering more services [30]. This proposed method covers two issues of the business process management: firstly, how to identify the business process that describes the stakeholder's needs?; and secondly, how to model the business process in order to identify all the sub-processes within the selected business process and establish a hierarchy among the identified processes?

\subsubsection{Process extraction}


To extract the business process, the proposed method uses the concept of the bubble diagram. A bubble diagram is a tool that many business and IT analysts use in the very first phase of the design process. It provides an easy way of identifying the business process including goals as well the connections between them. An inventory control system in a medical company has been used as case study, as shown in Figure 3, which is implemented using a bubble diagram. The primary goal of the medical company is the development of the system that maintains information about activities within firms such as: guaranteeing the delivery of products to consumers, sales, warehousing, ordering, manufacturing, and receiving. The company process has been divided into five phases where each phase describes the process, including goals. The goals and their activities are presented in the form of bubbles. In the first phase, we identify the process involving stakeholders and company rules and regulations in the form of "about company" which illustrates the company policies, service, history etc and "authentication" which describes how the company can control the following information: how to manage the validation of user accounts; how to create new user accounts; and how to delete existing user account information if required?

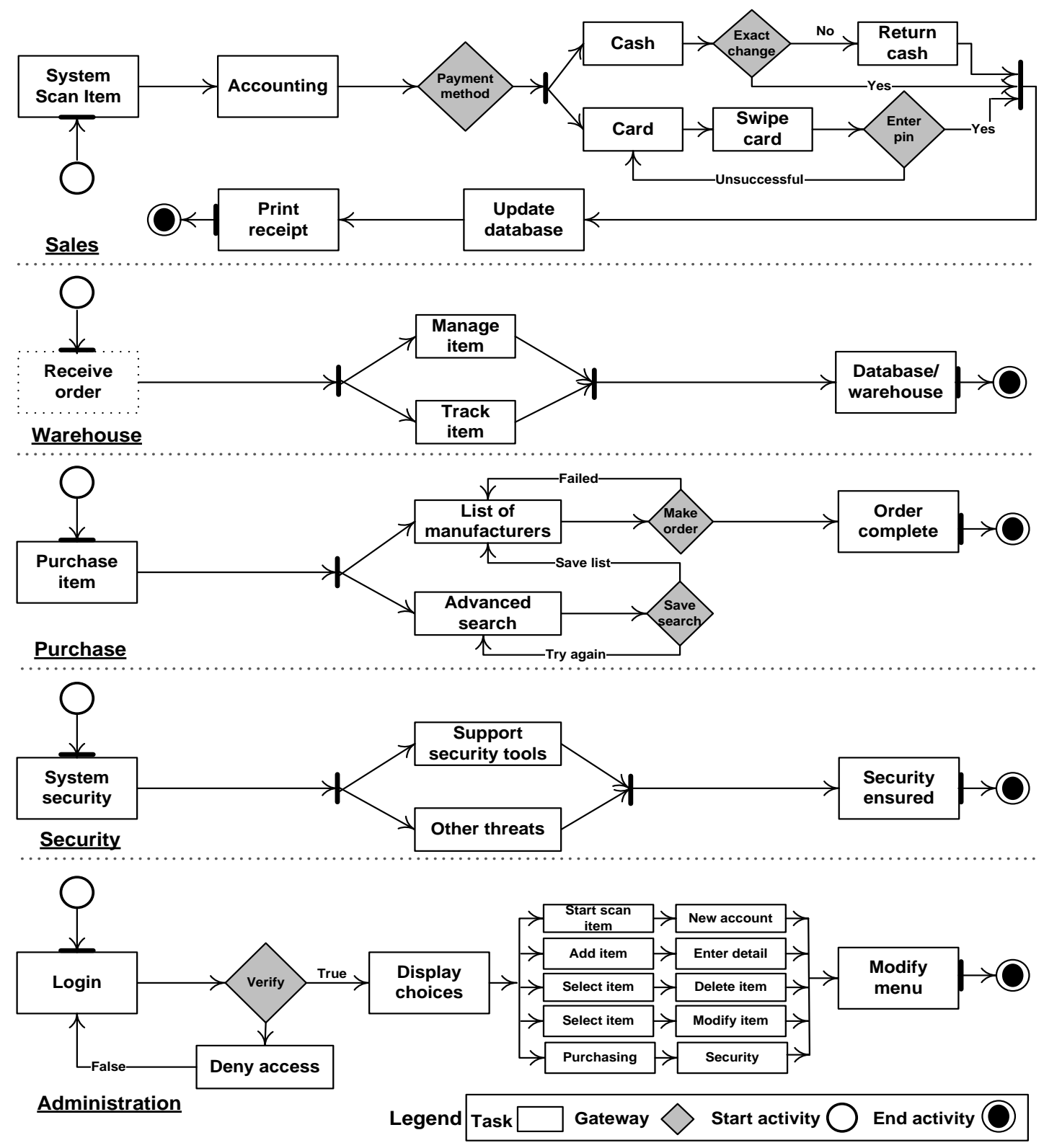

Fig. 4. Identification of business goals in the process. 


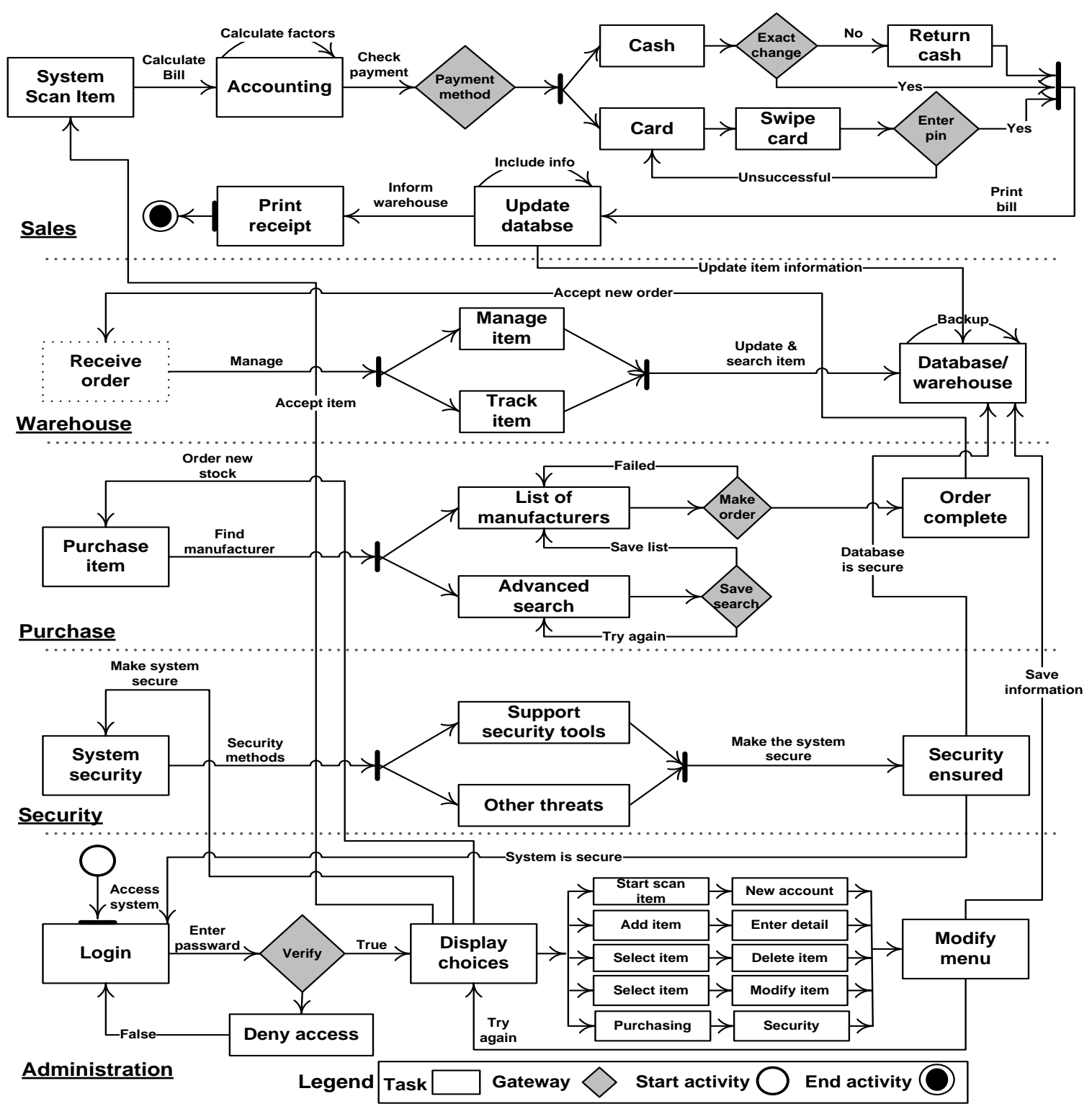

Fig. 5. Process modeling.

In phase 2, security in the form of CCTV and checkpoint alarm support as well as security threats such as human error, system failure etc, have been authenticated. In phase 3, we identify point of sale-related system features which include: scanning the item, calculating the bill, dealing with the customer's selected payment method, generating the invoice etc. In phase 3, we illustrate that one of the important components of a medical inventory system is the creation and maintenance of a sensible, valuable warehousing design. The warehouse is where the manager can easily trace an item's location by using the system, and can easily assign the location to the item when a new order arrives. Finally, in phase 5, we identify the purchase of a new product component using the inventory system, which contains a list of product manufacturers and their product type.

\subsubsection{Process modeling}

The notion of modeling business processes is used to represent the activities of an enterprise; therefore, the process can be analyzed and enhanced. Once the business process has been identified, we use business process modeling notation (BPMN) [22] in order to model the process. BPMN was developed by the 
business process management initiative group and is widely accepted by business analysts and business process researchers. The primary objective of BPMN is to provide standard notations, which are simple and easy for developers and other business stakeholders to understand. It uses a standard modeling language to bridge the gap between the business model and implementation. The method of modeling the business process which is shown in Fig. 4 and Fig. 5 is divided into two stages. In stage 1, we model each identified goal within the medical inventory process separately, as shown in Figure 4. The first goal of the process is sale, where the system scans the customer's selected item and calculates the bill, as well as checking the customer's chosen payment method. If the payment method is accepted, the system automatically updates the company's database and prints the receipt or the system gives an error message of "unsuccessful" if the payment method is rejected.

The second goal of the process is warehousing, where the system is responsible for managing the database of the company's products. It must allow the company to trace the item within the warehouse as well as allowing the company to assign a location in the warehouse to newly arrived items. The third goal of the process is purchasing, where the system maintains a list of product manufacturers to enable the company to place new orders when there is no stock. The fourth goal of the process is system security, where system enables the company to identify the security related tools and provides awareness about other security threads such as human error or system failure. Finally, the fifth goal of the process is administration, where system secures the company process by providing the login information. When administration tries to access the system it asks user name and password. After entering the login information system verify it with the database, if it verified system allow admin to access the system features otherwise it deny access.

Once every goal within the business process has been identified, it is important to establish a link between the goals in order to construct the whole process in a way that represents the right decomposition of the process, including goals, in the right sequence where the process has one start and end point. In stage 2 of the process modeling, we link each explored goal in Fig. 4 and define a sequence among the goals, as shown in Fig. 5. The process in Figure 5 starts from the administration process goal, where the system asks for login information to access the system and ends with the process goal of sales, where the system prints the receipt. The process at this stage clearly depicts the process, including goals, and exactly what the system has to do and how it should do it, which positively influences the development of a successful IT system and influences the process of implementing strong business alignment with information technology.

\section{Conclusion}

In this paper, we have presented a business process extraction method in the context of aligning business with information technology. The method is based on the bubble diagram and is an extension of our previous work [18]. An inventory control system in a medical company was used as a case study in order to validate the method. The findings are as follows: (1) business process extraction is possible using a bubble diagram; (2) business process extraction and process modeling can positively influence the requirements engineering procedure in the IS development lifecycle; (3) the procedure of requirements engineering has a direct effect on the implementation of a successful IS; and (4) the implementation of an IS that meets the business needs can positively influence alignment between business and IT, as well as positively influence the business process.

Three major implications can be derived from the method for researchers, business analysts, and IS analysts. First, for researchers, aligning information technology with business is always a difficult job [18], and although researchers have been working on this issue for many years, business executives and managers still consider the problem as unsolved and rank it as the top problem of all organizational issues. 
This paper introduced a new approach to IT-business alignment, and the method was successfully validated when implemented in an inventory control system in a medical company to ensure successful alignment. Second, for business analysts, business process extraction and modeling is always a challenging task. This method defines a way to extract the business process and to model the business process which is easy for business analysts and other business stakeholders to implement. Third, for IS analysts, understanding and deriving the IS requirements of the business in context with IT-Business alignment is difficult due to the business process complexity, as one business process can carry more than one business goal and every goal is linked to each other. Our method defines a way in which the business process has been taken into account before commencing the development phase of IS, which has a positive impact on the clarification of the business process and IS requirements among IS staff.

\section{References}

[1] Bubenko, J. A. P., \& Stirna, J. (2001). EKD User Guide. Retrieved from http://www.dsv.su.se/ js/ekd_user_guide.html

[2] Ellis, C. A. C. A., \& Wainer, J. (1994). Goal-based models of collaboration. Collaborative Computing, 1(0), 61-86.

[3] González, J. L. D. V., \& Juan, S. D. (2007). Business process-driven requirements engineering: a goal-based approach. Proceedings of the 8th Workshop on Business Process Modeling, Development, and Support.

[4] Taylor, F. W. (1911). The principles of scientific management. New York: Harper Bros.

[5] Hammer, M. \& Champy, J. (1993).Reengineering the corporation: A manifesto for business revolution. Nicholas Brealey Publishing, London.

[6] Smith, H., \& Fingar,P. (2004). Business process management (BPM): The third wave. Journal of Information Systems, 22.

[7] Nurcan, S. E., Kaabi, A., Zoukar, R. I., \& Rolland, C. (2005). A strategy driven business process modelling approach. Business Process Management Journal, 11(6), 628-649.

[8] Bider, (2000). Business process modelling—concepts. Proceedings of PBPM'00.

[9] Eriksson, H., \& Penker, M. (2000). Business Modeling with UML, Wiley.

[10] Ranganathan, C., \& Dhaliwal, J. S. (2001). A survey of business process reengineering practices in Singapore. Information \& Management, 39(2), 125-134.

[11] Terziovski, M. F. P., \& Neill, O. P. (2003). Successful predictors of business process reengineering (BPR) in financial services. International Journal of Production Economics, 84(1), 35-50.

[12] Burlton, R. (2001). Business Process Management: Profiting From Process, Sams.

[13] Spanyi, A. (2003). Business Process Management is a Team Sport: Play it to Win!. Anclote Press Imprint of Meghan-Kiffer Press.

[14] Tripathi, U. K., Hinkelmann, K., \& Feldkamp, D. (2008). Life cycle for change management in business processes using semantic technologies. Journal of Computers, 3(1).

[15] Stamatis, D. H. (2004). Six Sigma Fundamentals: A Complete Guide to The system, Methods, and Tools. New York, Productivity Press.

[16] Becker, A. L., Prikladnicki, R., \& Audy, J. L. N. (2009). Strategic alignment of software process improvement programs using QFD. Proceedings of the 1st International Workshop on Business Impact of Process Improvements. Leipzig, Germany, 9-14.

[17] Reich, B. H., \& Benbasat, I. (1996). Measuring the linkage between business and information technology objectives. MIS Quarterly.

[18] Ullah, A.. \& Lai, R. (2011). Modeling business goal for business/IT alignment using requirements 
engineering. Journal of Computer Information Systems (USA), 51(3).

[19] Christopher, J. P., \& Zou, J. (2008). Non-functional requirements in business process modeling. Proceedings of the 5th Asia-Pacific Conference on Conceptual Modelling (APCCM2008).

[20] Sharp, H. F. A., \& Galal, G. (1999). Stakeholder identification in the requirements engineering process. Proceedings of the 10th International. Workshop on Database and Expert. Systems Applications.

[21] Maiden, N., \& Robertson, S. (2005). Integrating creativity into requirements processes: Experiences with an air traffic management system. Proceedings of the IEEE International Requirements Engineering Conference (RE).

[22] White, S. A. (2008). BPMN Modeling and Reference Guide. Future Strategies Inc, USA.

[23] Henderson, J. C., \& Sifonis, J. G. (1988). The value of strategic IS planning: Understanding consistency, validity, and IS markets. MIS Quarterly, 12(2), 187-200.

[24] McLean, E. R. \& Soden, J. V. (1977). Strategic Planning for MIS, New York-Wiley.

[25] Pollalis, Y. A. (2003). Patterns of co-alignment in information-intensive organizations: business performance through integration strategies. International Journal of Information Management, 23(6), 469-492.

[26] Luftman, J. A., Papp, R., \& Brier, T. (1999). Enablers and inhibitors of business-IT alignment. Communications of the Association of Information Systems, 11(1), 1-33.

[27] Kearns, G. S., \& Lederer, A. L. (2000). The effect of strategic alignment on the use of IS-based resources for competitive advantage. Journal of Strategic Information Systems, 9(4), 265-293.

[28] Reich, B. H., \& Benbasat, I. (2000). Factors that influence the social dimension of alignment between business and information technology objectives. MIS Quarterly, 24(1), 81-113.

[29] Ullah, A., \& Lai, R. (2010). A requirements engineering approach to improving IT-Business alignment. Proceedings of ISD, 19th International Conference on Information Systems Development, Prague, Czech Republic: Published in Springer Computer Science Lecture Notes.

[30] Pandey, M. (2017). Business Process Modelling in Software Requirements Engineering Context.

[31] Jalali, A., Ouyang, C., Wohed, P., \& Johannesson, P. (2017). Supporting aspect orientation in business process management. Software and Systems Modeling, 16(3), 903-925.

[32] Dave, B. (2017). Business process management-a construction case study. Construction Innovation, 17(1), 50-67.

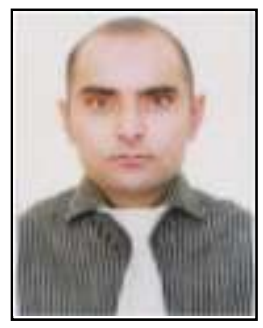

Azmat Ullah is with the School of Business, La Trobe University, Australia. He is expert in teaching applied information technology. His research interests include business-IT alignment, cloud computing, business process management, software engineering, software processes, requirements engineering, and information system development.

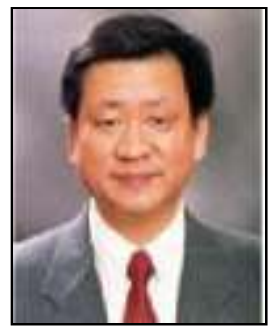

Richard Lai is with the Department of Computer Science and Information Technology at La Trobe University, Australia. Prior to joining La Trobe, he had spent more than 10 years in the computer and communications industry. He was ranked as the world's number one scholar in systems and software engineering consecutively for four years (1999-2002), according to an annual survey published in the Journal of Systems and Software. His current research interests include component-based software system, software measurement, requirements engineering, and global software development. 